NBER WORKING PAPER SERIES

PRIVATE VERSUS PUBLIC ENFORCEMENT OF FINES

A. Mitchell Polinsky

Working Paper No. $\underline{338}$

NATIONAL BUREAU OF ECONOMIC RESEARCH

1050 Massachusetts Avenue

Cambridge MA 02138

April 1979

The research reported here is part of the NBER's research program in Law and Economics. Any opinions expressed are those of the author and not those of the National Bureau of Economic Research. 


\section{PRIVATE VERSUS PUBLIC ENFORCEMENT OF FINES}

\section{A. Mitchell Polinsky $\stackrel{*}{*}$}

Abstract: Many undesirable activities are controlled by fines imposed by the government. In some contexts, such as antitrust violations and air pollution, it makes sense to consider giving the fine to a private party as an inducement for that party to discover and report the harmful behavior. This paper compares two "pure" forms of private enforcement--competitive and monopolistic-to public enforcement, allowing for the cost of enforcement to differ among the methods of enforcement. If the individuals engaging in the undesirable activity are potentially deterrable, then regardless of relative enforcement costs, private (competitive or monopolistic) enforcement leads to less enforcement than public enforcement and is socially inferior to public enforcement if the damage from the activity is sufficiently large. When private enforcement is cheaper than public enforcement, regulating private enforcers by paying them something different than the fine for each violator detected can achieve the socially most preferred outcome in the competitive case but not in the monopolistic case. If some individuals engaging in the activity are undeterrable, these results hold if some simple additional conditions are satisfied. Also, depending on relative enforcement costs, monopolistic enforcement may result in more or less enforcement than competitive enforcement.

Langdell 244

Harvard Law School

Cambridge, Massachusetts 02138

(617) 495-3539 


\section{INTRODUCTION}

Whenever the government attempts to control undesirable behavior it must choose a sanction to be imposed as well as an agent to do the enforcing. It is frequently the case that a particular sanction can be enforced within a variety of institutional arrangements. For example, some antitrust penalties in the United States are enforced both by public agencies--the Justice Department and the Federal Trade Commission--and private parties--the victims of

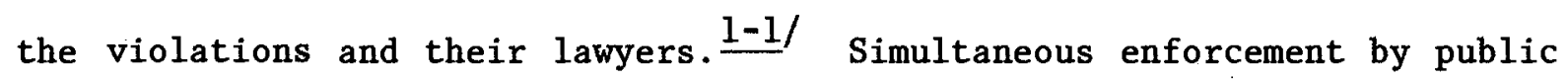
agencies and private parties also occurs in the control of air, water and noise pollution, securities code violations, consumer product safety, and land use. $1-2 /$ With a few exceptions (see below), economists have emphasized the choice of the sanction (e.g., taxes versus standards), taking the enforcer as given (usually the government). In contrast, this essay focuses on the choice of the enforcer for a particular type of sanction--a monetary payment or fine.

The most extensive discussion of the enforcement issue occurred in an exchange between Becker and Stigler (1974) and Landes and Posner (1975). Becker and Stigler suggested that private competitive enforcement of fines --in which the first individual or firm to discover and report the violation receives the fine--could duplicate the outcome under optimal public enforcement. $\frac{1-3 /}{}$ Landes and Posner, however, claimed that competitive enforcement would lead unambiguously to too much enforcement relative to optimal public enforcement. Their intuitive explanation (p. 15) was based on the following observations. Under public enforcement, if the probability of enforcement is unity, the fine should be set equal to the external damage caused by the activity. By raising the fine and lowering the probability, the same level of deterrence can be achieved at less cost. Under private enforcement, 
however, they argued that raising the fine would lead to a higher probability since profit-maximizing enforcers would be induced to invest more in enforcement. From this they concluded that there would be private overenforcement. Landes and Posner also argued that a private monopolist would overenforce for the same reason, but they concluded that the level of monopolistic enforcement would be less than in the competitive case (see below for the explanation). Both Becker and Stigler (1974) and Landes and Posner (1975) assumed in their analysis that the cost of enforcement (to achieve any given probability) was the same under competitive, monopolistic, and public enforcement. $1-4 /$ This assumption precluded welfare comparisons between private and public enforcement since, at best, the outcome under private enforcement might duplicate the outcome under optimal public enforcement.

The present paper analyzes the competitive, monopolistic, and public enforcement of fines allowing for the costs of enforcement to differ by the choice of the enforcer. There are a number of reasons to expect such differences. First, the benefits from coordinating enforcement--for example, avoiding duplication of investigative effort and exploiting economies of scale in information processing--are obtained under public enforcement and monopolistic enforcement, but not under competitive enforcement. Second, the profit motive might be imagined to lead to lower costs under either form of private enforcement relative to public enforcement. Third, when the revenue from fines under public enforcement is not sufficient to finance enforcement costs, there may be a deadweight burden incurred in making up the deficit from other sources. Conversely, if the fine revenue exceeds enforcement costs, the effective cost of enforcement would be lower. On balance, these considerations suggest that monopolistic enforcement may be cheaper than competitive enforcement, but that public enforcement could be more or less expensive than private enforcement. 
The general conclusions of this essay may be summarized briefly. Regardless of relative enforcement costs, private (competitive or monopolistic) enforcement leads in a wide range of circumstances to less enforcement than public enforcement, rather than more. This result, which tends to occur when the external damage from the violation is large, is easily explained. Under private enforcement, firms are willing to invest in enforcement only if they at least break even--their fine revenue must be at least as large as their enforcement costs. Under public enforcement, however, the optimal solution may result in fine revenue which is less than enforcement costs. This is particularly likely to occur when the damage from the violation is large since it is then optimal to deter many potential violators. Because the fine that can be imposed is limited (by the wealth of the potential violators), successful deterrence may require a high probability and correspondingly large enforcement costs. But successful deterrence and a limited fine may not generate much fine revenue. Even if private enforcement is less costly than public enforcement, private firms may not be able to break even at this level of deterrence and therefore would not be willing to enforce to this extent.

Public enforcement is socially preferable to private enforcement in many circumstances even when public enforcement is much costlier. This result closely parallels the previous one. The circumstances are the same ones which lead to private underenforcement, and the superiority of public enforcement tends to occur when the external damage from the violation is large. The explanation for this result is also straightforward. If the damage is large, it is socially optimal to deter many potential violators. If private enforcement leads to less enforcement than public enforcement, then public enforcement is more desirable in this respect. However, public enforcement may be costlier than private enforcement (for any given probability). But if 
the external damage is sufficiently large, the advantages of a higher level of enforcement will exceed the disadvantages of higher enforcement costs. Depending on relative enforcement costs, monopolistic enforcement may result in more or less enforcement than competitive enforcement. If the cost of enforcement is the same under competitive and monopolistic enforcement, then, as Landes and Posner (1975) showed, competitive enforcement may be greater than monopolistic enforcement. The reason is straightforward. Given a fine, the monopolist chooses a probability which generates (generally) positive profits. If, initially, competitive enforcement led to the same probability and profits, additional firms would enter until the profits were eliminated. The result would be a higher probability. However, because of the benefits from coordinating enforcement (see above), competitive enforcement may be more expensive than monopolistic enforcement. If competitive enforcement is sufficiently more expensive, then the level of competitive enforcement will be less than that of monopolistic enforcement. The high costs lead the competitive enforcement industry to shrink.

The above results suggest that any of the methods of enforcement may be socially preferable, depending on the costs of each method as well as on the magnitude of the external damage. This will be illustrated explicitly through an example in which enforcement costs are lowest under monopolistic enforcement, higher under competitive enforcement, and highest under public enforcement. In the example, when damages are low, monopolistic enforcement is socially preferable. Over an intermediate range of damages, competitive enforcement is most desirable. And for higher damages, public enforcement is superior.

The previous results assumed that the private enforcers were paid the fine for each violator caught. The following result, applicable when private enforcement is cheaper than public enforcement, is also shown. Regulating 
private enforcers by paying them something different than the fine for each violator detected can achieve the socially most preferred outcome in the competitive case but not generally in the monopolistic case. The problem in the monopolistic case is that it may not be possible to eliminate underenforcement. The discussion of this result is deferred.

The rest of the paper is organized as follows. Section 2 describes the basic model used to analyze the choice of enforcer. Section 3 discusses public enforcement. Section 4 presents sufficient conditions for private (competitive or monopolistic) underenforcement and for the superiority of public enforcement. Section 5 compares the levels of competitive and monopolistic enforcement. Section 6 contains an example which illustrates the results of sections 3 through 5 and shows the potential superiority of each method of enforcement. Section 7 considers public regulation of private enforcement. Section 8 briefly discusses two generalizations. An appendix contains proofs of some of the statements in the text. 
Individuals are assumed to have the same wealth and to be risk neutral. $2-1 /$ Each individual faces the same probability distribution of private gain from engaging in an activity which imposes damages on others. For example, everyone is assumed to be equally likely to need to double park in front of a hospital as a result of some emergency. (Also, each individual is equally likely to be the victim of others' damages.) An individual will engage in the activity if his realized private gain exceeds the expected fine. The following notation will be used:

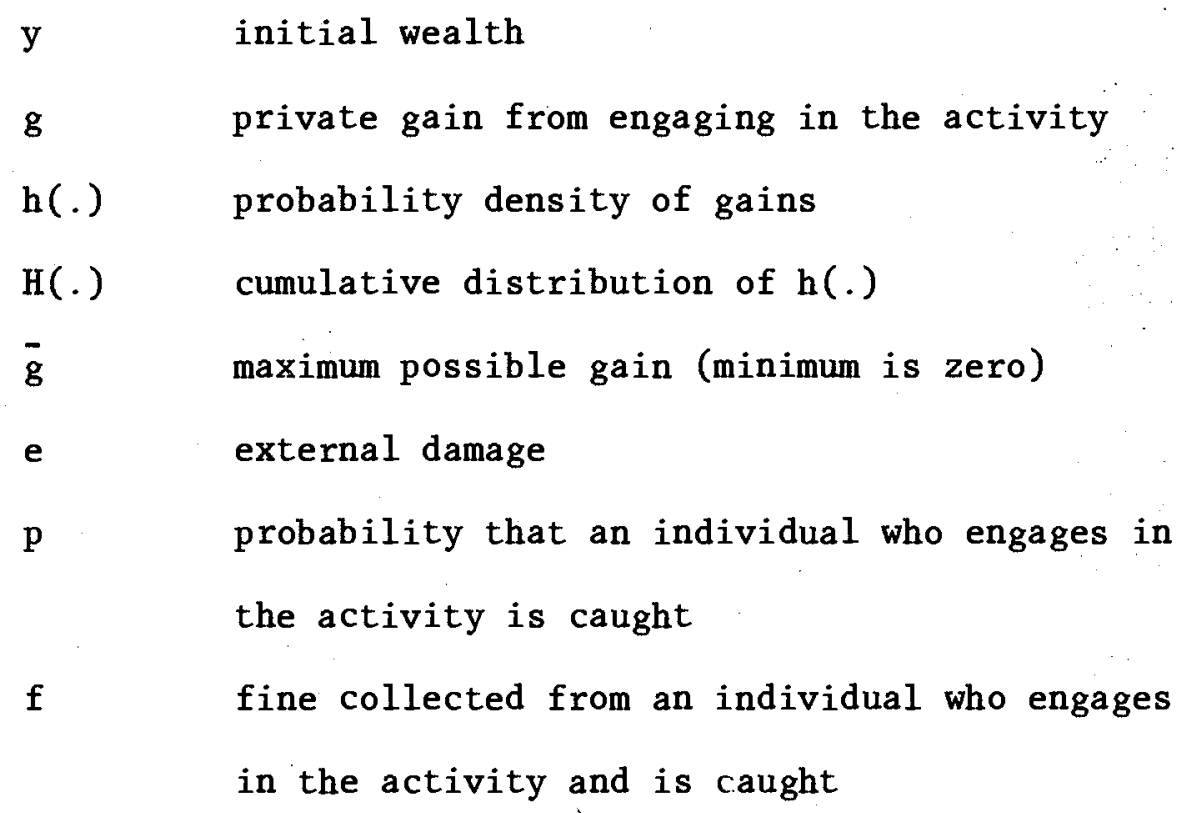

The population will be normalized so that total population equals unity. Thus, given an expected fine $\mathrm{pf},[1-\mathrm{H}(\mathrm{pf})]$ individuals will engage in the activity.

The cost of catching violators is assumed to depend on the fraction caught and on an exogenous shift parameter, $\lambda \geqq 1$, which will be used to represent differences in enforcement $\cos t s: \frac{2-2 /}{}$ 


$$
\begin{aligned}
& c(p, \lambda) \text { cost of catching fraction } p \text { of individuals who } \\
& \text { engage in the activity }(\partial c / \partial p>0, \partial c / \partial \lambda>0, \\
& \text { and } \left.\lim _{\lambda \rightarrow \infty} c(p, \lambda)=\infty \text { for all } p>0\right)
\end{aligned}
$$

In the competitive case, this cost function measures the aggregate cost for the industry, not the cost for each firm. The relevant values of the shift parameter under public, competitive, and monopolistic enforcement will be $\lambda_{p}$, $\lambda_{\mathrm{C}}$, and $\lambda_{\mathrm{M}}$.

Since everyone is identical (ex ante) and risk neutral, social welfare, $W$, equals the expected private gain from engaging in the activity, less the expected damage imposed, and less the cost of enforcement. It will be useful to emphasize that social welfare is a function of the enforcement cost shift parameter; therefore, let

$$
W(p, f, \lambda)=\int_{p f}^{\bar{g}} g h(g) d g-[1-H(p f)] e-c(p, \lambda) .
$$

Under public enforcement, the public enforcement agency's (hereafter the "agency") problem is to choose the probability and fine so as to maximize social welfare. Under monopolistic and competitive enforcement, the agency still chooses the fine to maximize social welfare, but the probability is

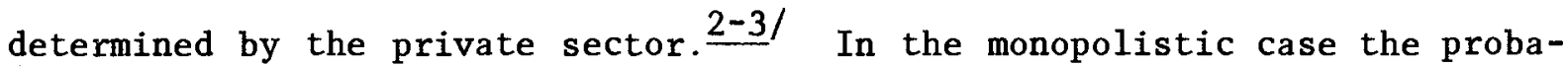
bility is implicitly determined by profit maximization (provided that profits are nonnegative), and in the competitive case by the condition that (in the long run) profits are zero. For given $p$ and $f$, profits equal fine revenue, $\mathrm{pf}[1-\mathrm{H}(\mathrm{pf})]$, less enforcement costs, c. In all three cases, the fine is assumed to be bounded by the wealth of individuals, y. $\frac{2-4 /}{\text { The three problems }}$ facing the agency may be stated in the following way. 
Public enforcement:

$$
\underset{p, f}{\operatorname{MAX}} \quad W\left(p, f, \lambda_{P}\right)
$$

The optimal values will be designated $\mathrm{p}^{*}$ and $\mathrm{f}^{*}$.

\section{Competitive enforcement:}

$$
\underset{f}{\operatorname{MAX}} W\left(p, f, \lambda_{c}\right)
$$

subject to

$$
\mathrm{pf}[1-\mathrm{H}(\mathrm{pf})]-\mathrm{c}\left(\mathrm{p}, \lambda_{\mathrm{C}}\right)=0 .
$$

The optimal value of $f$ will be $f_{C}$, and the resulting equilibrium value of $p$ will be $\mathrm{p}_{\mathrm{C}}$.

Monopolistic enforcement:

$$
\underset{f}{\operatorname{MAX}} W\left(p, f, \lambda_{M}\right)
$$

subject to

$$
\underset{\mathrm{MAX}}{\operatorname{Maf}} \operatorname{pf} \mathrm{H}(\mathrm{pf})]-\mathrm{c}\left(\mathrm{p}, \lambda_{\mathrm{M}}\right)
$$

The corresponding values of $p$ and $f$ will be $p_{M}$ and $f_{M^{*}}$ (Assuming $c(0, \lambda)=0$, (2.6) incorporates the constraint that profits are nonnegative since the monopolist is free to choose $\mathrm{p}=0$.)

This description of competitive and monopolistic enforcement assumes that private enforcers receive the fine when they have detected a violator. The feasibility and desirability of compensating private enforcers in other ways is discussed in section 7 . 


\section{PUBLIC ENFORCEMENT}

In this section the relevant features of public enforcement will be developed. After deriving the optimal fine and probability, the way in which the probability varies with the external damage will be discussed.

It is well known from the work of Becker (1968) and others that if individuals are risk neutral, the optimal fine equals their wealth. This result is easy to show in the present model. Suppose, to the contrary, that $f^{*}<y$. Let $k=p^{*} f^{*}$ be the expected fine. By raising $f^{*}$ to $y$ and lowering $\mathrm{p}^{*}$. to $\mathrm{k} / \mathrm{y}$, the expected fine is maintained at $\mathrm{k}$. Since individuals' decisions whether to engage in the activity are unaffected, the first two terms in the social welfare function (2.1)--private gains and external damages--are unaffected. The third term, enforcement costs, is reduced since the probability of catching violators has fallen. Note that the optimality of the fine equal to individuals' wealth does not depend on the magnitude of the external damage e.

Given $f^{*}=y$, the optimal probability is determined implicitly by the first order condition with respect to the probability (assuming a unique interior maximum); after some manipulation this may be written as

$$
[e-p y] \frac{\partial H}{\partial p}=\frac{\partial c}{\partial p} \text {. }
$$

This condition has a natural interpretation. As the probability is raised marginally, enforcement costs rise by $\partial c / \partial p$. However, fewer individuals engage in the activity since the expected fine has risen; this effect is represented by $\partial H / \partial p$. Each individual who does not now engage in the activity reduces external costs by e but forgoes private gains of py. Since $\partial c / \partial p>0$ and $\partial H / \partial p>0$, it must be that $e>$ py for (3.1) to be satisfied; in other 
words, at the optimum there is a net benefit to society from each individual who is induced not to engage in the activity. Thus, (3.1) states that the marginal benefits of further deterrence from raising the probability just equal the marginal costs of raising the probability.

Since the optimal fine equals individual wealth regardless of the external damage, e, one would expect that an increase in $e$ would lead to a higher optimal probability. In fact, it is straightforward to show that

$$
\frac{d p^{*}}{d e}=-\frac{\partial H / \partial p}{[S O C]}>0
$$

where "SOC" refers to the second order condition, which is negative.

As the external damage approaches zero, the optimal probability approaches zero:

$$
\lim _{e \rightarrow 0} p^{*}(e)=0
$$

Although a proof of (3.3) is contained in the appendix, the result is intuitively plausible. The maximum possible benefit from deterrence is e (at most everyone violates the rule). Since it is never worth spending more on enforcement than the benefits from deterrence, spending must approach zero as e approaches zero. This implies that the optimal probability must approach zero.

As the external cost approaches infinity, the optimal probability approaches an upper bound:

$$
\lim _{e \rightarrow \infty} p^{*}(e)=\min [\bar{g} / y, 1]
$$

The proof of (3.4) is contained in the appendix. The intuition is as follows. $3-1 /$ If the maximum possible gain, $\bar{g}$, is less than (or equal to) individuals' wealth, y, then everyone is potentially deterrable (that is, could 
be deterred by some $\mathrm{p} \leqq 1$ and some $\mathrm{f} \leqq \mathrm{y}) \cdot \frac{3-2 /}{}$ If the external damage they impose is sufficiently large, then it becomes worthwhile to deter everyone. To do so, the expected fine, $\mathrm{p}^{*} \mathrm{y}$, must equal $\overline{\mathrm{g}}$; that is, $\mathrm{p}^{*}=\overline{\mathrm{g}} / \mathrm{y}$. Any higher $p$ creates unnecessary costs. If $\bar{g}$ is greater than $y$, then individuals whose gains exceed $y$ are undeterrable. But, if e is sufficiently large, it becomes worthwhile to deter everyone else; to do so, $\mathrm{p}^{*}$ must equal 1 . In brief, (3.4) states that as the external damage approaches infinity, it becomes worthwhile to do everything possible to deter individuals from violating the rule.

None of the above results depends on the level of the enforcement cost shift parameter $\lambda_{\mathrm{P}}$ : However, the level of $\lambda_{\mathrm{P}}$ obviously affects the probability which is optimal for any external damage e. It is easy to show that

$$
\frac{d p^{*}}{\mathrm{~d} \lambda}=\frac{\partial^{2} \mathrm{c} / \partial \mathrm{p} \partial \lambda}{[\mathrm{SOC}]}<0
$$

assuming $\partial^{2} \mathrm{c} / \partial \mathrm{p} \partial \lambda>0$. In other words, the optimal probability falls at each level of the external damage when the schedule of enforcement costs rises, provided that marginal enforcement costs also rise. 


\section{PRIVATE VERSUS PUBLIC ENFORCEMENT}

This section explains sufficient conditions for two results. The first is that the expected fine under private enforcement, $\mathrm{p}^{\circ} \mathrm{f}^{\circ}$, is less than the expected fine under public enforcement, $\mathrm{p}^{*} \mathrm{f} *$. The second is that social welfare is higher under public enforcement even though the cost of enforcement (for any probability) may be much higher under public enforcement. Both of these results occur when the external damage is "large." The comparison of private and public enforcement when the external damage is small will be discussed in the context of an example in section 6 .

Proposition 1: Regardless of how the public agency chooses the fine under private enforcement, regardless of whether the private enforcement industry is competitive or monopolistic, and regardless of the relative costs of private and public enforcement, there will be private underenforcement $\left(p^{\circ} f^{\circ}<p^{*} f^{*}\right)$ for sufficiently large external damages (e) if

(i) all individuals who engage in the activity are potentially deterrable $(\bar{g} \leqq y)$, or if

(ii) there are some undeterrable individuals $(\bar{g}>y)$ and any one of the following conditions holds:

(a) the number of undeterrable individuals $(1-\mathrm{H}(\mathrm{y}))$ is sufficiently sma11,

(b) the wealth of individuals (y) is sufficiently small,

(c) the cost of enforcement approaches infinity as the probability approaches unity $\left(\lim _{p \rightarrow 1} c(p, 1)=\infty\right)$.

The proof of Proposition 1 is presented in the appendix. The basic idea behind the proof is relatively simple. Suppose first that all individuals are potentially deterrable, that is $\overline{\mathrm{g}} \leqq \mathrm{y}$. In this case the expected fine 
under optimal public enforcement approaches complete deterrence, $\bar{g}$, as the external cost, e, approaches infinity: $f^{*}=y$ and $p^{*}$ approaches $\bar{g} / y$. If the expected fine under private enforcement, $\mathrm{p}^{\circ} \mathrm{f}^{\circ}$, were to approach complete deterrence, fine revenue would approach zero. Since enforcement costs are positive for any positive $p$, profits would be negative. Thus, $p^{\circ} f^{\circ}$ must be less than $\bar{g}$, so there exists some e beyond which $\mathrm{p}^{\circ} \mathrm{f}^{\circ}<\mathrm{p}^{*} \mathrm{f}^{*}$. When there are some undeterrable individuals, that is $\overline{\mathrm{g}}>\mathrm{y}$, this argument does not apply directly because there will always be some fine revenue under private enforcement. In this case the expected fine under public enforcement approaches maximum possible deterrence as $e$ approaches infinity: $f^{*}=y$ and $p^{*}$ approaches 1. For the expected fine under private enforcement to approach maximum possible deterrence, $\mathrm{p}^{\circ}$ would have to approach 1 . Any one of the three additional conditions is sufficient to imply negative profits when $p^{0}$ is in the neighborhood of 1 , regardless of $f^{\circ}(\leqq y)$. The conditions with respect to the number of undeterrable individuals, [1-H(y)], and their wealth, $y$, lead to negative profits by making fine revenue sufficiently small, while the last condition implies negative profits by making enforcement costs sufficiently large. Thus, $\mathrm{p}^{\circ}$ must be bounded away from 1 for all e, so there again exists some e beyond which $p^{\circ} f^{\circ}<p^{*} f^{*}$.

Put another way, the basic point of Proposition 1 is the following. Under private enforcement, the only feasible combinations of the probability and the fine are those which result in fine revenue at least as large as enforcement costs. But when the external damage is high, the optimal probability and fine under public enforcement are both high; this implies low fine revenue--because of successful deterrence--and large enforcement costs. The high probability and fine may not be compatible with private enforcement, even if private enforcement is less costly than public enforcement. Hence, private underenforcement. $\underline{4-1 /}$ 
Proposition 2: Regardless of how the public agency chooses the fine under private enforcement, regardless of whether the private enforcement industry is competitive or monopolistic, and regardless of how much costlier public enforcement is than private enforcement (for any $\lambda_{\mathrm{P}}<\infty$ ), public enforcement is socially preferable to private enforcement for sufficiently large external damages if any of the conditions stated in Proposition 1 hold.

The proof of Proposition 2 is also contained in the appendix. The intuition behind the proof is easily explained. If any of the conditions of Proposition 1 are satisfied, there exists some level of the external damage beyond which $p^{\circ} f^{\circ}<p^{*} f^{*}$. The higher level of public enforcement has three consequences for social welfare (2.1). First, the private gains from engaging in the activity are reduced because more potential violators are deterred. Second, the external damages are reduced for the same reason. Third, enforcement costs may be higher because $\mathrm{p}^{*}$ may exceed $\mathrm{p}^{\circ}$, and $\lambda_{\mathrm{P}}$ may exceed both $\lambda_{\mathrm{C}}$ and $\lambda_{M}$. The first and the third effects, which reduce social welfare, can have only a limited impact since at most everyone is deterred and the cost of enforcement is finite for $p<1$ and $\lambda<\infty$. The second effect, which improves social welfare, has an unlimited impact as the external damage increases. Thus, public enforcement will lead to higher social welfare if the damage is sufficiently large. 


\section{COMPETITIVE VERSUS MONOPOLISTIC ENFORCEMENT}

This section states a sufficient condition for the result that the expected fine under competitive enforcement, $p_{C} f_{C}$, is lower than the expected fine under monopolistic enforcement, $p_{M} f_{M}$. This result occurs when the cost of competitive enforcement is "large" relative to that of monopolistic enforcement. The relationship between competitive and monopolistic enforcement when enforcement costs are similar will be described in the context of an example in the next section.

Proposition 3: Regardless of how the public agency chooses the fine under private enforcement and regardless of how costly monopolistic enforcement is (for any $\lambda_{M}<\infty$ ), competitive enforcement will be less than monopolistic enforcement $\left(p_{C} f_{C}<p_{M} f_{M}\right)$ if competitive enforcement is sufficiently $\operatorname{costly}\left(\lambda_{\mathrm{C}}\right.$ sufficiently large $)$.

The proof, which is included in the appendix, is based on the following reasoning. If $p_{C}{ }_{C}$ is at least as large as $p_{M} f_{M}$, then $p_{C}$ must be at least as large as some positive probability $\left(p_{M} f_{M} / y\right.$, otherwise $\left.p_{C} f_{C} \leqq p_{C} y<p_{M} f_{M}\right)$. Even at this probability, competitive enforcement costs grow without bound as $\lambda_{C}$ increases. Since there is only a finite amount of fine revenue that can possibly be raised, profits in the competitive enforcement industry must become negative for $\lambda_{C}$ sufficiently large. This implies that $p_{C}{ }_{C}$ must be below $p_{M} f_{M}$ if $\lambda_{C}$ is large enough.

Obviously, if $\lambda_{C}$ is very large, it may be preferable for the public agency to choose $f_{C}=0$ because competitive enforcement is not worth its costs at any level of enforcement. This is not why $p_{C} f_{C}<p_{M} f_{M}$ when $\lambda_{C}$ is large. An example is presented in the next section in which $0<p_{C} f_{C}<p_{M} f_{M}$ over a range of $\lambda_{C}$, when both $f_{C}$ and $f_{M}$ are chosen by the public agency to maximize social welfare. 


\section{AN EXAMPLE}

In this section an analytically solvable example of the complete model will be described. Besides illustrating the results of the previous three sections it will show how the public agency sets the fine under private enforcement, and how the potential superiority of each method of enforcement depends on the relative costs of enforcement and the magnitude of the external damage.

The example is characterized by two assumptions. First, the probability density of private gains is uniform:

$$
h(g)=\text { constant }=1 / \bar{g} \text {. }
$$

Second, enforcement costs are proportional to the probability of catching violators and to the enforcement cost shift parameter:

$$
c(p, \lambda)=\lambda k p
$$

where $\lambda \geqq 1$ and $k$ is the cost per unit of probability when $\lambda=1$.

Given these assumptions, social welfare (2.1) becomes:

$$
W(p, f, \lambda)=\left[\frac{\bar{g}}{2}-\frac{p^{2} f^{2}}{2 \bar{g}}\right]-\left[1-\frac{p f}{\bar{g}}\right] e-\lambda k p
$$

The first term (in brackets) represents expected private gains, the second expected external damages, and the third enforcement costs.

Public enforcement. Since $f^{*}=y,(6.3)$ is maximized just over $p$. The result is: $: \frac{6-1 /}{}$
(6.4) $\mathrm{p}^{*}=\left\{\begin{array}{l}0, \\ \frac{\mathrm{ye}-\lambda \mathrm{k} \overline{\mathrm{g}}}{\mathrm{y}^{2}} \\ \min [\overline{\mathrm{g}} / \mathrm{y}, 1]\end{array}\right.$
$\mathrm{e} \leqq \mathrm{e}^{*}$
$\mathrm{e}^{*}<\mathrm{e} \leqq \mathrm{e}^{*}+\min [\bar{g}, \mathrm{y}]$,
e $>e^{*}+\min [\bar{g}, y]$,

where 


$$
\mathrm{e}^{*}=\lambda \mathrm{k} \overline{\mathrm{g}} / \mathrm{y} \text {. }
$$

There are three regions in terms of the external damage, e. For e sufficiently small, it is not worthwhile controlling the activity at all since the benefits--lower damages--are less than the costs--enforcement costs and foregone private gains. For intermediate e the optimal probability is positive and increasing with $e$. Depending on whether $\bar{g} \lessgtr y$, it increases to 1 or $\bar{g} / y$ at some $e$ and remains there for all higher $e$.

Monopolistic enforcement. The monopolist's profit function is:

$$
\Pi(p, f)=p f\left[1-\frac{p f}{\bar{g}}\right]-\lambda k p
$$

The monopolist's profit maximizing choice of $p$, given $f$, is:

$$
p_{M}=\frac{(f-\lambda k) \bar{g}}{2 f^{2}} \text { for } f \geqq \lambda k \text {. }
$$

Substituting (6.7) into (6.3) and maximizing over $f$ gives the following result:

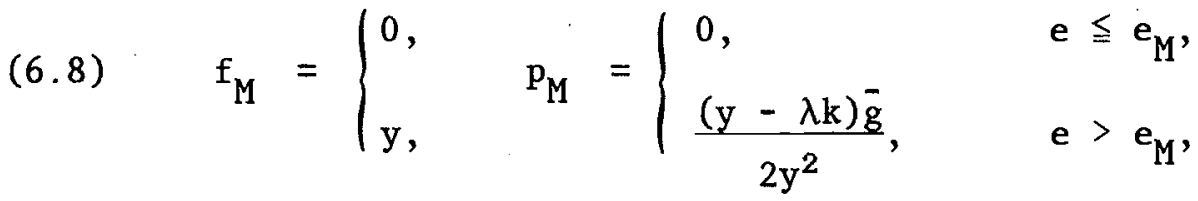

where

$$
e_{M}=(3 \lambda k+y) \bar{g} / 4 y .
$$

(When $f_{M}=y$, the monopolist's profits are strictly positive.)

There are two regions in terms of the external damage. For e sufficiently small, it is not worth controlling the activity, so the public agency sets the fine at zero. For larger e, it is worth controlling the activity. In this example the optimal fine under monopolistic enforcement jumps from zero to $y \cdot \frac{6-2 /}{}$

Competitive enforcement. The competitive industry's aggregate profits must equal zero in equilibrium. Thus, 


$$
\Pi(p, f)=p f\left[1-\frac{p f}{\bar{g}}\right]-\lambda k p=0 .
$$

Solving for $\mathrm{p}$ gives:

$$
p_{C}=\frac{(f-\lambda k) \bar{g}}{f^{2}} \text { for } f \geqq \lambda k
$$

Substituting (6.11) into (6.3) and maximizing over $f$ leads to:

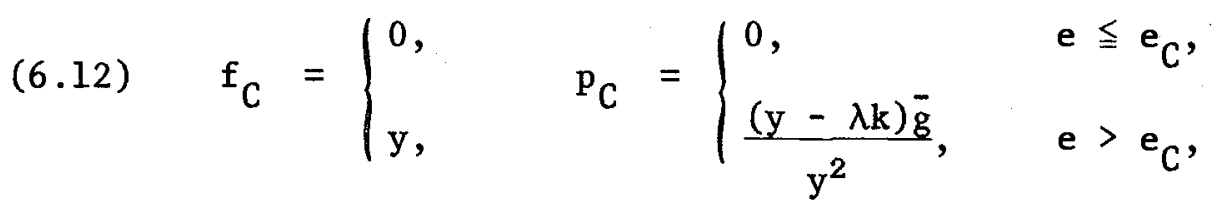

where

$$
e_{C}=(\lambda k+y) \bar{g} / 2 y .
$$

The discussion following (6.9) applies here as well.

The public, monopolistic, and competitive enforcement results are summarized in Figure 1. The solid lines show in each case how the expected fine varies with the level of external damages assuming that enforcement costs are at their minimum, $\lambda=1$. Each of the schedules would shift, of course, if $\lambda$ were higher. The dashed line labeled "c-locus" is the locus of starting points $\left(e_{C}\right)$ and levels $\left(p_{C} f_{C}\right)$ for competitive enforcement defined by the feasible range of $\lambda>1$. For example, the competitive schedule when $\lambda=3$ is illustrated. The "m-locus" is defined similarly for monopolistic enforcement. Under public enforcement, the expected fine schedule would shift to the right in a parallel way as $\lambda$ increases. Figure $l$ is constructed on the assumptions that $\overline{\mathrm{g}}=\mathrm{y}$, so all individuals are potentially deterrable, and that $\mathrm{k}=.25 \mathrm{y}$, that is, one-quarter of society's income would be required to catch everyone when $\lambda=1$. None of the important qualitative results in Figure 1 depend on these assumptions.

Figure 1 illustrates the result of Proposition 1 concerning private underenforcement. Since everyone is potentially deterrable, condition (i) of 
Proposition 1 applies--a high enough external damage is sufficient to guarantee private underenforcement. Figure 1 shows that the minimum level of $e$ required before underenforcement is observed may be different under competitive and monopolistic enforcement. Figure 1 also shows that the level of private enforcement may exceed that of public enforcement when damages are low. For example, when $\lambda=1$ for each method of enforcement, there is a region of overenforcement for both competitive and monopolistic enforcement. However, depending on relative enforcement costs, there may be no external damage at which private overenforcement occurs. Compare for example, the competitive schedule in Figure 1 when $\lambda=3$ to the public schedule when $\lambda=1$.

The intuitive explanation of private underenforcement (see sections 1 and 4) suggested that private underenforcement tends to occur when it is optimal under public enforcement to deter "many" or "most" potential violators (since fine revenue is then likely to be less than enforcement costs). However, Figure 1 indicates indirectly that private underenforcement can occur even when most potential violators are not deterred. For example, suppose $\lambda=1$ for both monopolistic and public enforcement. At the external damage at which $p_{M} f_{M}$ first becomes less than $p * f *$ (this occurs, coincidentally, at $\mathrm{e}_{\mathrm{C}}$ in Figure 1), $\mathrm{p}^{*} \mathrm{f} \%=.375 \mathrm{y}$. Since private gains are uniform between 0 and $\bar{g}=y$, this implies that even when it is optimal under public enforcement to deter as few as $38 \%$ of the potential violators, monopolistic enforcement is less than public enforcement. If monopolistic enforcement is costlier than public enforcement, then this underenforcement result can occur at an even lower level of public deterrence.

Figure 1 also illustrates the result of Proposition 3 that competitive enforcement will be less than monopolistic enforcement if competitive enforce- 
FIGURE I

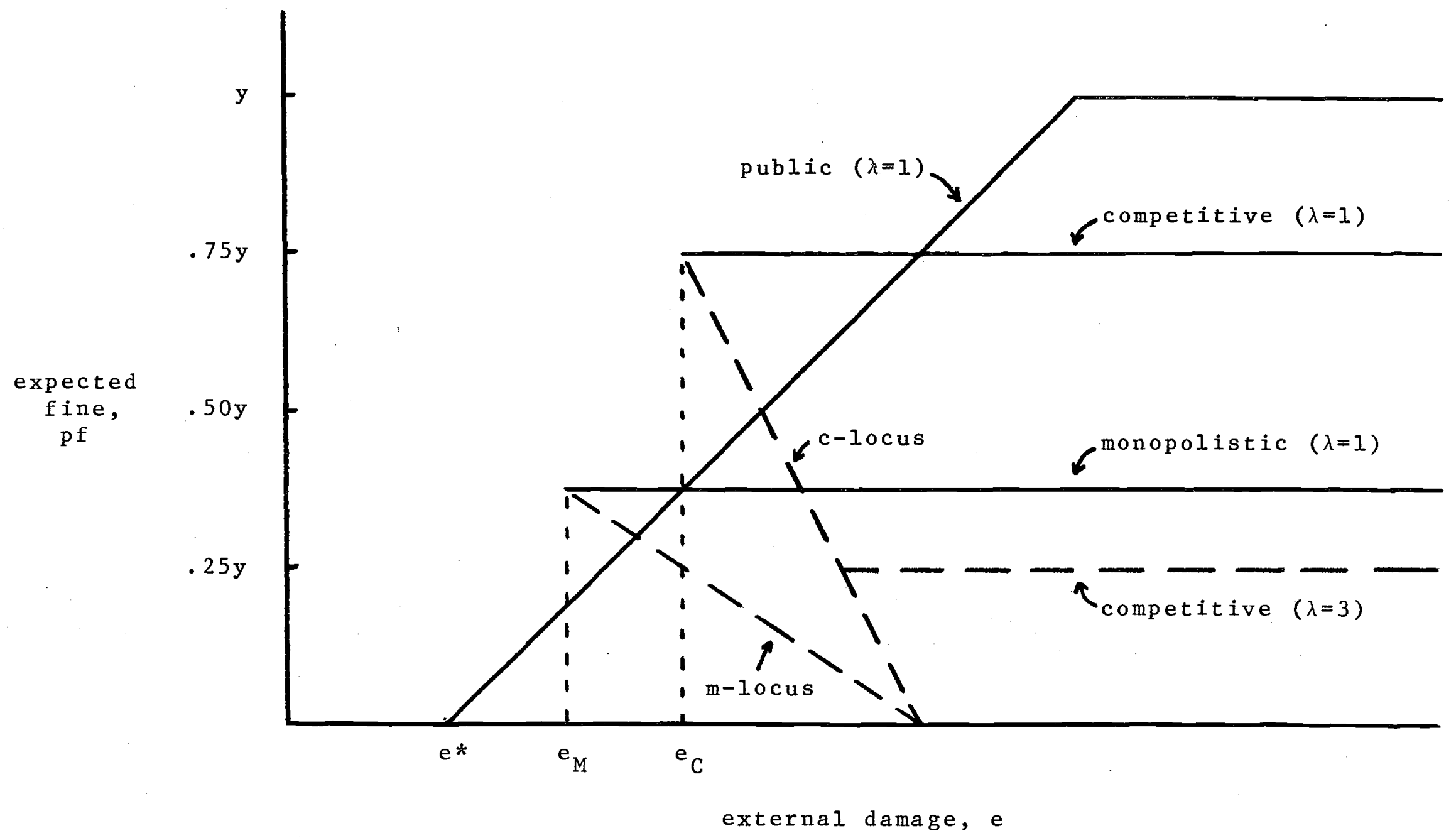


ment is sufficiently more expensive. For example, if $\lambda=1$ for monopolistic enforcement and $\lambda=3$ for competitive enforcement, this result is shown explicitly. However, there are many combinations of $\lambda_{M}$ and $\lambda_{C}$ which also lead to this result. From (6.8) and (6.12) it is easy to show that the expected fine under competitive enforcement will be less than the expected fine under monopolistic enforcement if $2 \lambda_{C}-\lambda_{M}>y / k$. Since Figure 1 was constructed on the assumption that $k=.25 y, y / k=4$ in this case. That competitive enforcement may exceed monopolistic enforcement is also shown in Figure 1 when $\lambda_{\mathrm{C}}=\lambda_{\mathrm{M}}=1$.

An example of welfare comparisons among public, competitive, and monopolistic enforcement is illustrated in Figure 2. It is assumed that monopolistic enforcement is least expensive $(\lambda=1)$, competitive enforcement is more costly $(\lambda=1.5)$, and public enforcement is most expensive $(\lambda=2)$. The corresponding expected fine schedules are shown in Figure 2. A fourth expected fine schedule, labeled "first-best $(\lambda=1), "$ is included as a benchmark; this is the schedule that would have been derived under public enforcement if public enforcement were as cheap as possible $(\lambda=1)$. The darkened portion of each schedule indicates the range over which it is the socially preferred method of enforcement. When damages are very low (below $e_{M}$ in Figure 2), violations are not worth controlling at all. As damages increase, monopolistic enforcement then becomes preferable because it is cheapest and "reasonably" close to first-best enforcement. For even higher damages, competitive enforcement is best because it is then closer to first-best enforcement than monopolistic enforcement is, and it is still cheaper than public enforcement. Finally, for sufficiently high damages, public enforcement becomes preferable despite its costs because it leads to the highest level of enforcement, coinciding with the level of first-best enforcement. 
FIGURE 2

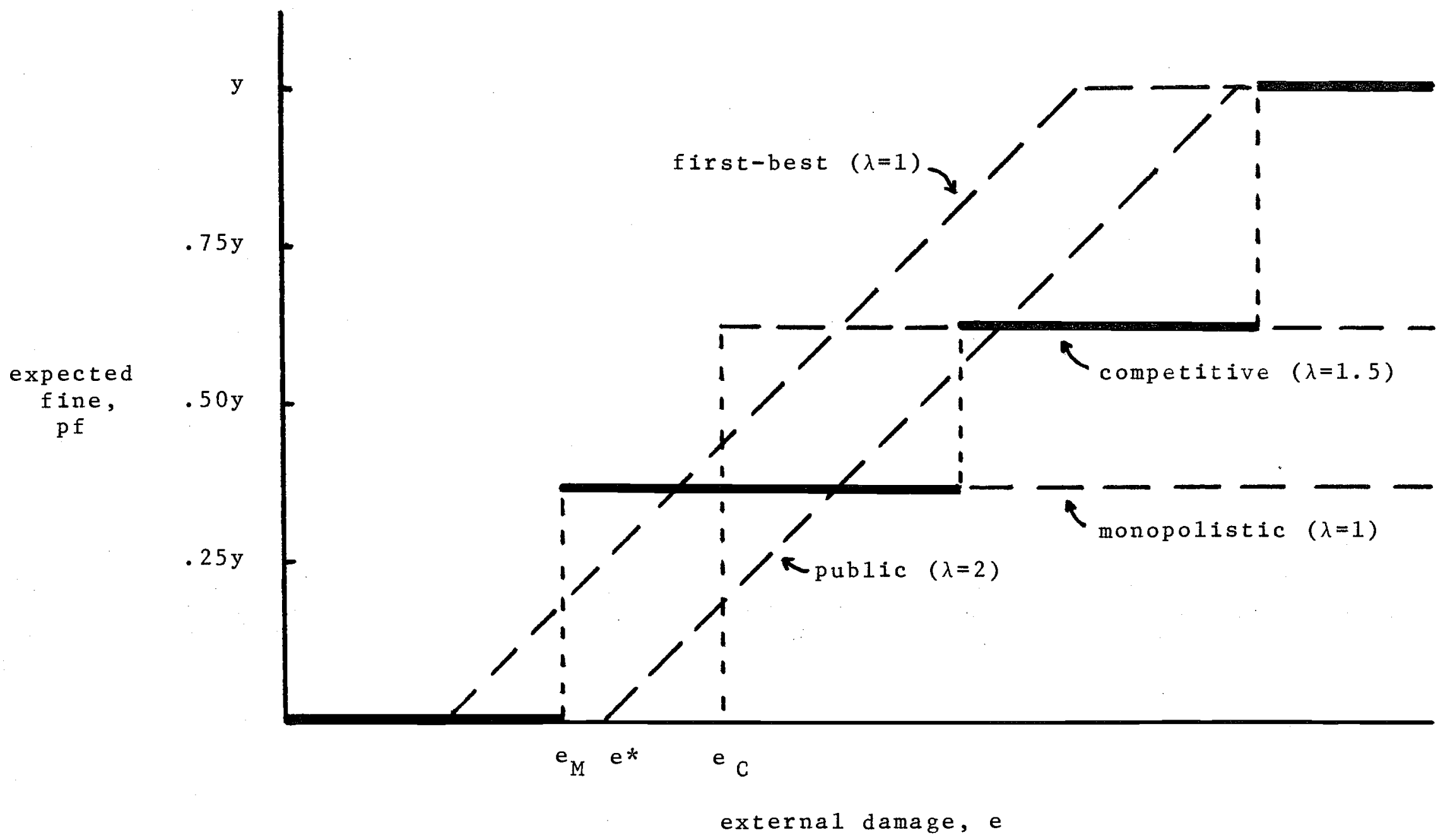


Thus, Figure 2 illustrates the result of Proposition 2 concerning the superiority of public enforcement. Since everyone is potentially deterrable in the example, a high enough external damage is sufficient to guarantee this result.

Public enforcement may also be socially preferable at low levels of damages even when public enforcement is costlier than private enforcement. For example, suppose $\lambda=1$ for monopolistic enforcement and $\lambda=1+\varepsilon$ for public enforcement, where $\varepsilon>0$ may be arbitrarily small. At the level of external damages $e_{M}$ in Figure 2, social welfare under monopolistic enforcement is the same as when the activity is not controlled at all (by construction of $e_{M}$, and strictly less than social welfare under first-best enforcement (since it is desirable to begin using first-best enforcement at a lower level of damages). But as $\varepsilon$ approaches zero, social welfare under public enforcement approaches social welfare under first-best enforcement. Thus, for $\varepsilon$ sufficiently sma11, public enforcement will be socially preferable to monopolistic enforcement for external damages just above $e_{M}$ in Figure 2 . This does not imply that public enforcement is more desirable at all higher levels of the external damage. To the contrary, at the level of the external damage in Figure 2 where the monopolistic schedule crosses the first-best schedule, monopolistic enforcement is socially preferable. It duplicates the first-best outcome, whereas public enforcement is costlier since $\lambda>1$ (as a result, of the higher costs, the level of public enforcement would be lower). By Proposition 2, however, public enforcement eventually becomes preferable again for sufficiently high external damages. Thus, the optimal choice of enforcer may depend in a complicated way on relative enforcement costs and the level of the external damage. 


\section{PUBLIC REGULATION OF PRIVATE ENFORCEMENT}

When public enforcement is more expensive than private enforcement, it is natural to ask whether some form of public regulation of private enforcement can achieve the first-best outcome--what the public enforcement agency would choose if it could enforce as cheaply as the private enforcers. It is obvious that this outcome can be reached in principle if the agency appropriately compensates private enforcers on the basis of the probability of detecting violators or, equivalently, the number of violators deterred. However, it may be very expensive or impossible for the agency to verify claims by private enforcers that they had achieved a high probability and thereby deterred a large number of individuals. This would certainly be true in the context of activities which can be concealed like securities fraud or price fixing (but may not be true in other contexts like pollution). $\frac{7-1 /}{}$ Since this difficulty does not arise if the compensation is based on the number of violators actually caught, an interesting question is whether there exists some compensation schedule based on this information which can achieve the first-best outcome. When the compensation schedule takes the simple form of paying private enforcers a fixed amount per person caught, this amount will be referred to as a bounty, $b$.

Proposition 4: Under competitive enforcement, there exists a bounty which can achieve (or come arbitrarily close to) the first-best outcome.

The proof of this result is straightforward. To achieve the first-best outcome the public agency must choose $f=y$ (for the reason discussed in section 3 ). Given $f=y$ and $a$ bounty $b$, the zero profit condition for the competitive industry is

$$
\Pi=\mathrm{pb}[1-\mathrm{H}(\mathrm{py})]-\mathrm{c}(\mathrm{p}, \lambda)=0 .
$$

Solving (7.1) for b leads to 


$$
b(p)=c(p, \lambda) / p[1-H(p y)] .
$$

This determines a finite bounty for every $p>0$ provided that enforcement costs, $c$, are not infinite and that the number of individuals engaging in the activity, [1-H(py)], is not zero. For enforcement costs to be infinite or the number of violators to be zero, the optimal probability would have to be at its upper bound, $\bar{p}=\min [\overline{\mathrm{g}} / \mathrm{y}, 1]$. In this case, a probability can be achieved under competitive enforcement which is arbitrarily close to the optima' probability. The remaining detail in the proof is to show that there does not exist more than one probability which satisfies the zero profit condition for the same bounty. Intuitively, one would expect that the higher the probability desired, the higher the bounty required, so this should not be a problem. This detail is left to the appendix.

Proposition 5: Under monopolistic enforcement, there does not exist a bounty which can correct (even approximately) for underenforcement if all individuals are potentially deterrable $(\bar{g} \leqq y)$ or if the number of undeterrable individuals $(1-H(y))$ is sufficiently small.

The proof of this proposition is contained in the appendix. To understand the basic idea behind this result, suppose the monopolist maximizes just bounty revenue, $\mathrm{pb}[1-\mathrm{H}(\mathrm{py})]$, rather than revenue minus enforcement costs. This is equivalent, of course, to maximizing the number of violators caught, $p[1-H(p y)]$, regardless of the bounty $b$. If all individuals are potentially deterrable and the probability were at the level which deterred everyone, obviously no individuals would be caught. Thus, no matter how large the bounty is, it would pay the monopolist to choose a lower probability than this one. Taking enforcement costs into account tends to lower the profit maximizing probability even further. Since the optimal probability approaches the probability which deters everyone as the external damage 
approaches infinity (3.4), there will be monopolistic underenforcement which cannot be corrected by any bounty. If there are some undeterrable individuals, the same reasoning applies as long as the monopolist would increase the number of violators caught by lowering the probability from unity. If the number of undeterrable individuals is sufficiently sma11, then lowering the probability will have this effect--the reduction in the number of undeterrable individuals caught will be offset by the increase in the number of potentially deterrable individuals caught.

Proposition 5 can be illustrated in terms of the example in the previous section. Assuming, as there, that $\bar{g}=y$ and $k=.25 y$, and given $f_{M}=y$, it is easy to show that the monopolist's profit maximizing probability is $\mathrm{p}_{\mathrm{M}}=$ $.5-(y / .125 b)$. Thus, although $p_{M}$ is increasing with $b$, as $b$ approaches infinity, $\mathrm{p}_{\mathrm{M}}$ only approaches .5 .

The reason for the success of a bounty in the competitive case and its failure in the monopolistic case is not entirely surprising. In both cases, a higher bounty induces a higher probability. $\frac{7-2 /}{}$ The higher probability in turn reduces the number of individuals engaging in the activity. While each competitive firm treats the number of individuals engaging in the activity as fixed, the monopolist takes the actual reduction into account. When the probability becomes high enough, this effect may become severe enough to put a ceiling on the probability that the monopolist is willing to choose.

In general, the amount of compensation can be any function of the number of violators caught. It may seem that limiting the function to the special case of a fixed payment per person caught is what prevents the first-best outcome from being achieved under monopolistic enforcement. The following proposition shows that this is not the case.

Proposition 6: Under monopolistic enforcement, there does not exist any schedule of compensation based on the number of violators caught which can 
correct for underenforcement if either of the conditions stated in Proposition 5 holds.

The proof of this proposition is outlined here. Let $n(p)=p[1-H(p y)]$ be the number of violators actually caught, and let $\hat{p}>0$ be the probability at which $n($.$) reaches its maximum (if there is more than one such probability,$ let $\hat{\mathbf{p}}$ be the smallest). The discussion following Proposition 5 indicated that if either of the conditions stated there holds, a reduction in the probability from the upper bound probability, $\bar{p}=\min [\overline{\mathrm{g}} / \mathrm{y}, 1]$, increases the number of persons caught; that is $n^{\prime}(\bar{p})<0$. Thus, $\hat{p}<\bar{p}$. Since $n($.$) is$ continuous (assuming $h($.$) is continuous) and n(0)=0$, for every probability between $\hat{p}$ and $\bar{p}$ there exists a probability between 0 and $\hat{p}$ which leads to the same number of violators caught. As a result, no probability between $\hat{p}$ and $\bar{p}$ can be achieved--the monopolist would always choose the corresponding probability below $\hat{p}$ since it would lead to the same compensation and lower enforcement costs (if there is more than one such probability below $\hat{p}$, the monopolist will choose the lower of these).

There is a potential difficulty with regulating private enforcers by paying them something different than the fine which has not been incorporated into the above analysis. If private enforcers are taxed (a bounty less than the fine), then, as Landes and Posner (1975, p. 24) have suggested, ". . both the apprehended offenders and the enforcer would be better off privately negotiating a payment that was less than the statutory fine but greater than the fine minus the tax." If private enforcers are paid more than the fine, there would be an incentive to fabricate offenses. These considerations do not necessarily imply, however, that this form of regulation cannot still improve matters over unregulated private enforcement. (Moreover, as Becker and Stigler (1975) have forcefully argued, analogous problems of malfeasance may arise under public enforcement.) 


\section{CONCLUDING REMARKS}

There are two ways in which the present model can be made more realistic without affecting the basic results. If the individuals being controlled are risk averse rather than risk neutral, then, as Polinsky and Shavell (forthcoming) have shown, the optimal fine under public enforcement is generally less than individuals' wealth and the optimal probability is generally higher than it would be if they were risk neutral. However, it still appears to be true that if the external damage is high enough, it is optimal under public enforcement to deter as many individuals as possible, possibly everyone. $\frac{8-1 /}{\text { Then, }}$ for the reasons discussed in this paper, (unregulated) private enforcement may lead to underenforcement, and public enforcement would therefore be superior if the external damage is large enough. The result concerning the comparison of competitive and monopolistic enforcement and those concerning public regulation of private enforcement are essentially unaffected.

The second way to make the model more realistic would be to include the number of violators in the enforcement cost function as well as the probability of catching them. Enforcement costs would increase, everything else equal, if the probability rises or if the number of violators rises. Then, raising the probability might reduce costs since the number of individuals engaging in the activity would fall. However, it seems plausible to assume that some costs must be incurred to set a high probability even if, as a result of that probability, no one actually engages in the activity. In other words, to achieve complete deterrence (if that is possible) some "stand-

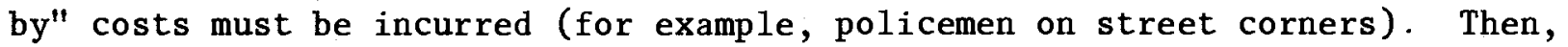
again for the reasons discussed here, (unregulated) private enforcers may not be willing to enforce to the same extent as public enforcers and public enforcement will be preferable if the damages are sufficiently large. The other results are essentially unchanged or can be reformulated. 


\section{APPENDIX}

Assumptions used in some proofs are carried over to others without restating them. Also, $c(p, \lambda)$ is written simply as $c(p)$ where this does not lead to confusion.

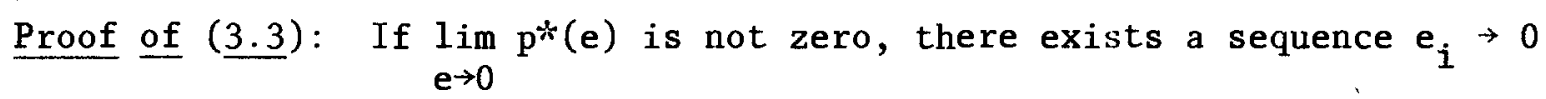
such that $\mathrm{p}^{*}\left(\mathrm{e}_{i}\right) \geqq \varepsilon$ for some $\varepsilon>0$ and all $i$. This leads to a contradiction. Let W(.) be social welfare as a function of $p$. It is easy to show that if $e=e_{i}$,

$$
\begin{aligned}
W(0)-W\left(p^{*}\right) & =\int_{0}^{p^{*} y} g h(g) d g-H\left(p^{* y}\right) e_{i}+c\left(p^{*}\right) \\
& >\int_{0}^{\varepsilon y} g h(g) d g-e_{i},
\end{aligned}
$$

which is positive for sufficiently small $e_{i}$, contradicting the presumed optimality of $\mathrm{p} *\left(\mathrm{e}_{\mathbf{i}}\right)$.

Proof of (3.4): It is assumed that $c(p)<\infty$ for all $p<\bar{p}$, where $\overline{\mathrm{p}}=\min [\overline{\mathrm{g}} / \mathrm{y}, 1]$. For the reason noted in section $3, \mathrm{p}^{*} \leqq \overline{\mathrm{g}} / \mathrm{y}$ when $\overline{\mathrm{g}}<\mathrm{y}$. Thus, if $\lim _{e \rightarrow \infty} p^{*}(e)$ is not $\bar{p}$, there exists a sequence $e_{i} \rightarrow \infty$ such that $\mathrm{p}^{*}\left(\mathrm{e}_{\mathbf{i}}\right) \leqq \overline{\mathrm{p}}-\varepsilon$ for some $\varepsilon>0$ and all $\mathrm{i}$. This leads to a contradiction. Let $\hat{\mathrm{p}}$ be any probability satisfying $\overline{\mathrm{p}}-\varepsilon<\hat{\mathrm{p}}<\overline{\mathrm{p}}$. It is straightforward to show that if $e=e_{i}$,

$$
\begin{aligned}
W(\hat{p})-W\left(p^{*}\right) & =-\int_{p^{* y}}^{\hat{p} y} g h(g) d g+\left[H(\hat{p} y)-H\left(p^{*} * y\right)\right] e_{i}-\left[c(\hat{p})-c\left(p^{*}\right)\right] \\
& >-\bar{g}+[H(\hat{p} y)-H((\bar{p}-\varepsilon) y)] e_{i}-c(\hat{p})
\end{aligned}
$$


which is positive for sufficiently large $e_{i}$, contradicting the presumed optimality of $p^{*}\left(e_{i}\right)$. Note that this argument does not depend on any assumption about $\lim c(p)$. If $\lim c(p)<\infty$, then a stronger version of (3.4) can be $\mathrm{p} \rightarrow \overline{\mathrm{p}} \quad \mathrm{p} \rightarrow \overline{\mathrm{p}}$

proved: there exists an $\tilde{e}<\infty$ such that for all e $>\tilde{e}, p^{*}=\min [\bar{g} / y, 1]$.

Proof of Proposition 1: The proof: will refer to the monopolist, although it applies directly to the competitive case as well. Regardless of how the public agency chooses the fine under monopolistic enforcement, let $p^{\circ}$ and $f^{\circ}$ be any equilibrium probability and fine combination. The resulting profits to the monopolist are

$$
\Pi\left(p^{\circ}, f^{\circ}\right)=p^{\circ} f^{\circ}\left[1-H\left(p^{\circ} f^{o}\right)\right]-c\left(p^{\circ}\right)
$$

Let $\mathrm{z}$ be the expected fine $\mathrm{p}^{\circ} \mathrm{f}^{\circ}$. If $\mathrm{f}^{\circ}<\mathrm{y}$, raise the fine to $\mathrm{y}$ and lower the probability to $\mathrm{z} / \mathrm{y}$, so that the expected fine is constant. Since revenue would be constant and enforcement costs would be lower, the monopolist's profits would be higher. Thus, for any equilibrium expected fine $z$, the monopolist's profits are less than or equal to

$$
\tilde{\Pi}(z)=z[1-H(z)]-c(z / y) .
$$

First case: $\overline{\mathrm{g}} \leqq \mathrm{y} . \quad$ Since $\lim _{\mathrm{e} \rightarrow \infty} \mathrm{p} *(\mathrm{e})=\min [\overline{\mathrm{g}} / \mathrm{y}, 1]$ and $\mathrm{f}^{*}=\mathrm{y}$, the expected fine under optimal public enforcement approaches $\bar{g}$. At this expected fine the monopolist's profits are less than or equal to

$$
\tilde{\Pi}(\bar{g})=-c(\bar{g} / y)<0 .
$$

By the continuity of $\tilde{\Pi}$, there exists a $\delta>0$ such that $\tilde{\Pi}(z)<0$ for all $z$ satisfying $\bar{g}-\delta<z \leqq \bar{g}$. Thus, $p^{\circ} f^{\circ} \leqq \bar{g}-\delta$ and, given a sufficiently large e, $p * f * \bar{g}-\delta$.

Second case: $\bar{g}>\mathrm{y}$. The expected fine under public enforcement approaches y. At this expected fine the monopolist's profits are less than or equal to 


$$
\tilde{\Pi}(y)=y[1-H(y)]-c(1) .
$$

If $[1-H(y)]$ or $y$ are sufficiently small, or if $\lim c(p)=\infty, \tilde{\Pi}(y)$ will be $\mathrm{p} \rightarrow 1$

negative. Assuming $\tilde{\Pi}(y)$ is negative, the previous argument implies $p^{\circ} f^{\circ}<p^{*} f^{*}$ for sufficiently large e.

Proof of Proposition 2: If any of the conditions stated in Proposition 1 hold, then (from the proof of that proposition) there exists a $\delta>0$ such that $\mathbf{p}^{\circ} \mathrm{f}^{\circ} \leqq \overline{\mathrm{p} y}-\delta$ for all e, where $\overline{\mathrm{p}}=\min [\overline{\mathrm{g}} / \mathrm{y}, 1]$. Let $\hat{\mathrm{p}}$ be any probability satisfying $\overline{\mathrm{py}}-\delta<\hat{\mathrm{p} y}<\overline{\mathrm{p} y}$, and let $\hat{W}($.$) be social welfare as a function of$ e assuming $p=\hat{p}, f=y$, and $\lambda=\lambda_{p}<\infty$. Also, let $W^{\circ}($.$) be social welfare$ under private enforcement assuming $\lambda=\lambda^{\circ}<\lambda_{\mathrm{P}}$. It is straightforward to show that

$$
\begin{aligned}
\hat{W}(e)-W^{\circ}(e) & =-\int_{p^{\circ} f^{\circ}}^{\hat{p} y} g h(g) d g+\left[H(\hat{p} y)-H\left(p^{\circ} f^{\circ}\right)\right] e-\left[c\left(\hat{p}, \lambda_{P}\right)-c\left(p^{\circ}, \lambda^{o}\right)\right] \\
& >-\bar{g}+[H(\hat{p} y)-H(\bar{p} y-\delta)] e-c\left(\hat{p}, \lambda_{P}\right),
\end{aligned}
$$

which is positive for sufficiently large e. Since social welfare under public enforcement is at least as large as $\hat{W}(e)\left(\hat{p}\right.$ may not equal $\left.p^{*}(e)\right)$, the result follows.

Proof of Proposition 3: Fix $\lambda_{M}<\infty$. Suppose $p_{C} f_{C} \geqq p_{M} f_{M}>0$ for all $\lambda_{C}$. Then $p_{C} \geqq p_{M} f_{M} / y>0$ for all $\lambda_{C}$. This leads to a contradiction. Competitive profits are

$$
\begin{aligned}
& p_{C} f_{C}\left[1-H\left(p_{C} f_{C}\right)\right]-c\left(p_{C}, \lambda_{C}\right) \\
& <y-c\left(p_{M} f_{M} / y, \lambda_{C}\right)
\end{aligned}
$$

which is negative for sufficiently large $\lambda_{C}$, contradicting the zero profit condition. Thus, $p_{C} f_{C}<p_{M} f_{M}$ for large enough $\lambda_{C}$. 
Proof of Proposition 4: It remains to be shown that $\mathrm{db} / \mathrm{dp}>0$. From (7.2), writing $\partial c / \partial p$ as $c^{\prime}$,

$$
\operatorname{sign}(d b / d p)=\operatorname{sign}\left\{c^{\prime} p[1-H]-c([1-H]-p h y)\right\} .
$$

It is assumed that the profit function $\Pi$ is strictly concave in $p$. This implies that at the $p>0$ where profits are zero,

$$
\partial \Pi / \partial \mathrm{p}=\mathrm{b}[1-\mathrm{H}]-\mathrm{bphy}-\mathrm{c}^{\prime}<0
$$

Using this result,

$$
\begin{gathered}
c^{\prime} p[1-H]-c([1-H]-p h y)>c^{\prime} p[1-H]-c\left(c^{\prime} / b\right) \\
=c^{\prime}(p[1-H]-(c / b))=0
\end{gathered}
$$

where the last equality follows from the zero profit condition. Thus, db/dp $>0$.

Proof of Proposition 5: Setting $f=y$ and the bounty at $b$, the monopolist's profits are

$$
\Pi(p)=p b[1-H(p y)]-c(p)
$$

Let $\bar{p}=\min [\bar{g} / y, 1]$ and assume that $c^{\prime}(\bar{p})<\infty$ (the result will clearly also hold if $\left.c^{\prime}(\overline{\mathrm{p}})=\infty\right)$. It is sufficient to show that

$$
\Pi^{\prime}(\bar{p})=b\{[1-H(\bar{p} y)]-\bar{p} y h(\bar{p} y)\}-c^{\prime}(\bar{p})<-c^{\prime}(\bar{p})
$$

regardless of $b$, since this implies $p_{M}<\bar{p}-\varepsilon$ for some $\varepsilon>0$. If $\bar{g} \leqq y$, $[1-H(\bar{p} y)]=[1-H(\bar{g})]=0$, so $\Pi^{\prime}(\bar{p})\left\langle-c^{\prime}(\bar{p})\right.$. If $\left.\bar{g}\right\rangle y, \Pi^{\prime}(\bar{p})\left\langle-c^{\prime}(\bar{p})\right.$ if $[1-H(\bar{p} y)]=[1-H(y)]$ is sufficiently small. Since, by $(3.4), \underset{e \rightarrow \infty}{\lim } p^{*}(e)=\bar{p}$, the result follows. 
NOTES

*) Harvard University and National Bureau of Economic Research. Work on this paper was supported by the National Science Foundation through a grant (SOC 78-20159) to the law and economics program of the National Bureau of Economic Research. Any opinions expressed are those of the author and not those of the NBER. Helpful comments were provided by Lucian Bebchuk, Michael Boskin, Robert Clark, Robert Cooter, Lewis Kornhauser, William Landes, Richard Posner, Robert Prichard, Daniel Rubinfeld, Steven Shavell, and participants in seminars at various universities during the 1978-79 academic year.

1-1/ See, for example, Elzinga and Breit (1976). A similar policy has recently been adopted in Canada. See Prichard and Trebilcock (1978). In the antitrust context, as in many other contexts (see note 1-2 below), it is usually not the exact same sanction which is enforced both privately and publicly, but rather, close substitutes. For example, the Justice Department can seek to impose a fine on an antitrust violator, whereas a private party can seek "treble damages."

1-2/ See, for example, Clark (forthcoming), Ellickson (1973), and Mashaw (1975). See also Dam (1975).

1-3/ Because of other considerations (public malfeasance), Becker and Stigler suggested a preference for private enforcement. From a somewhat different perspective, their discussion of private enforcement has been formalized and supported by Harris and Raviv (1978).

1-4/ This assumption was implicit in Becker and Stigler's discussion and explicit in Landes and Posner's model (p. 10). Landes and Posner did discuss informally (pp. 29-30) why enforcement costs might differ.

2-1/ Risk neutrality was also assumed by Becker and Stigler (1974) and Landes and Posner (1975). The present results would not be affected if in- 
dividuals were risk averse; see section 8 .

2-2/ In general, the cost also depends on the number of violators. This effect is omitted since it is not central to the present argument. All of the main results carryover to the more general case; see section 8 .

2-3/ It is assumed that an equilibrium exists and is unique for each fine under private enforcement.

2-4/ It may not be possible to increase the maximum fine by including the private gain $g$. The gain may be concealed if it is money ("Swiss bank account"), or it may be nonmonetary ("saving your spouse's life by speeding to a hospital").

3-1/ The intuitive explanation presumes that enforcement costs are finite for all probabilities. This leads to a stronger statement than (3.4); see the appendix.

3-2/ Individuals for whom $g=y$ are indifferent between engaging and not engaging in the activity when $p=1$ and $f=y$. Since nothing is affected, it is assumed that they would choose not to engage in the activity.

4-1/ In response to an earlier version of this paper, William Landes and Richard Posner discovered that the possibility of private underenforcement was implicit in their (1975) analysis. They now maintain that an additional assumption is necessary in order to guarantee their private overenforcement result. The assumption is that the wealth of injurers is not a binding constraint on the choice of the fine under private enforcement. But this assumption is not likely to be satisfied when the external damage is "large" since the enforcement agency would probably wish to choose a high fine in order to achieve a high level of deterrence.

6-1/ In describing the results for the three methods of enforcement, the subscripts with respect to $\lambda$ are omitted for notational simplicity. 
6-2/ In general the optimal fine probably would rise continuously as the external damage increases.

7-1/ Since it is assumed in the model that potential violators know the probability of being detected by private enforcers, it may seem peculiar to assume that the public enforcement agency may not be able to determine this probability. However, a more realistic assumption is that neither potential violators nor the enforcement agency are able to estimate with much accuracy the true probability under private enforcement. The agency may not wish to compensate private enforcers on the basis of such imperfect information. As long as potential violators perceive a higher probability when the true probability has risen, the basic features of the present analysis would not be affected.

7-2/ In the competitive case, this is shown in the proof of Proposition 4 in the appendix. In the monopolistic case, it is easy to show that $\mathrm{dp} / \mathrm{db}=$ $-[1-\mathrm{H}] /[\mathrm{SOC}]>0$.

8-1/ Suppose everyone is potentially deterrable. As the damage goes to infinity, if everyone is deterred, no one would bear any risk. If there are some undeterrable individuals, their bearing of risk must be taken into account. However, as the damage goes to infinity, if the probability approaches unity and the fine approaches wealth, the risk bearing would disappear. Thus, it seems in both cases that the optimal solution as the damage approaches infinity is not affected by risk aversion. 


\section{REFERENCES}

Becker, Gary S., "Crime and Punishment: An Economic Approach," Journal of Political Economy, Vol. 76, No. 2 (March/April 1968), pp. 169-217.

Becker, Gary S., and George J. Stigler, "Law Enforcement, Malfeasance, and the Compensation of Enforcers," Journal of Legal Studies, Vol. 3, No. 1 (January 1974), pp. 1-18.

Clark, Robert C., Managerial Loyalty: The Search for an Optimal Corporate Law (tentative title), forthcoming.

Dam, Kenneth W., "Class Actions: Efficiency, Deterrence, and Conflict of Interest," Journal of Legal Studies, Vol. 4, No. 1 (January 1975), pp. 47-73.

Ellickson, Robert C., "Alternatives to Zoning: Covenants, Nuisance Rules, and Fines as Land Use Controls," University of Chicago Law Review, Vol. 40, No. 4 (Summer 1973), pp. 681-781.

Elzinga, Kenneth G., and William Breit, The Antitrust Penalties: A Study in $\underline{\text { Law }}$ and Economics (New Haven: Yale University Press, 1976).

Harris, Milton, and Artur Raviv, "Some Results on Incentive Contracts with Applications to Education and Employment, Health Insurance, and Law Enforcement," American Economic Review, Vol. 68, No. 1 (March 1978), pp. 20-30. Landes, William M., and Richard A. Posner, "The Private Enforcement of Law," Journal of Legal Studies, Vol. 4, No. 1 (January 1975), pp. 1-46.

Mashaw, Jerry L., "Private Enforcement of Public Regulatory Provisions: The 'Citizen Suit'," Class Action Reports, Vol. 4, No. 1 (January-February 1975), pp. 29-42.

Polinsky, A. Mitche11, and Steven Shavel1, "The Optimal Tradeoff Between the Probability and Magnitude of Fines," American Economic Review, forthcoming. Prichard, J. Robert S., and Michael J. Trebilcock, "Class Actions and Private Law Enforcement," University of New Brunswick Law Journa1, Vo1. 27 (June 1978), pp. 5-17. 